\title{
Synthesis and properties of new sulfonated naphthalenic polyimides as proton exchange membrane for fuel cell applications
}

\author{
L. Zhao, Y.D. Huang, * Y.J. Song, Y.M. Piao
}

*Department of Applied Chemistry, Harbin Institute of Technology, P.O. Box 410, No.92 West Da-Zhi Street, Harbin 150001, P. R. China; fax: 86-451-8641-8270; email: ydhuang.hit1@yahoo.com.cn

(Received: 17 October, 2007; published: 3 April, 2008)

\begin{abstract}
The diamine monomer, 5-amino-2-(p-aminophenyl)benzoxazole(ABO), was successfully synthesized and a series of new naphthalenic sulfonated polyimides (SPIs) were prepared from 1,4,5,8-naphthalenetetracarboxylic dianhydride (NTDA), 2,2'-benzidinedisulfonic acid (BDSA), ABO and 1,10diaminedecane (DADE) using one-step high temperature polymerization method. Their structures were characterized by FTIR, ${ }^{1} \mathrm{HNMR}$ and TG-DSC. The sulfonated degree of the SPI copolymers was controlled through varying the molar ratio of BDSA to the non-sulfonated diamines. Tough and transparent membranes with the typical polyimide brown colour were prepared by casting from the polymer solution. They showed clear anisotropic membrane swelling in water with larger dimensional changes in the thickness direction of membrane. The sulfonated polyimide membrane containing $20 \mathrm{~mol} \%$ benzoxazole moieties (SPI-20) showed desirable thermal stability with the decomposition temperature of $272{ }^{\circ} \mathrm{C}$ and mechanical stability with the maximum stress of $42 \mathrm{MPa}$. The proton conductivity $\left(6.2 \times 10^{-}\right.$ ${ }^{3} \mathrm{~S} / \mathrm{cm}$ ) of SPI-20 membrane was comparable to that of Nafion ${ }^{\circledR} 117$ membrane measured under the same condition $\left(9.8 \times 10^{-3} \mathrm{~S} / \mathrm{cm}\right)$. The effects of temperature on the proton conductivity, and highly anisotropic proton conductivity in the thickness and plane direction were also investigated.
\end{abstract}

\section{Introduction}

Proton exchange membrane fuel cells (PEMFC) have been considered as promising power sources in vehicular transportation and portable applications for their high efficiency, high power density, low noise, reduced pollution, and the simplicity of system. Proton exchange membranes are the key components of PEMFC systems. At present, perfluorosulfonic acid membranes, such as DuPont's Nafion ${ }^{\circledR}$ membrane, are typically used as the proton exchange membranes in PEMFC due to their high proton conductivity, good mechanical strength, high thermal and chemical stability [1]. However, some disadvantages such as high cost, strong dependence of proton conduction on the water content of the membrane, and high methanol permeability seriously limit their industrial application [2]. Therefore, many efforts have gone into the development of the alternative membrane materials, which are not prone to such deleterious properties. Over the last decade, several new classes of protonconducting polymer electrolytes have been formed into membranes and their properties investigated. The aromatic polymers are particularly promising because they can be prepared in a wide great variety of chemical structures and can be chemically modified at potentially low cost. The major approach has been the 
attachment of sulfonic acid groups onto highly stable aromatic polymers, such as poly(ether ether ketones) [3-6], poly(aryl ether sulfone) [7-9], and polybenzimidazole $[10,11]$.

Recently, Sulfonated polyimides (SPIs) have been shown to be promising materials for polymer electrolyte membranes due to their good proton conductivity and relatively small geometrical changes upon swelling-deswelling, good thermal stability and mechanical durability, and low methanol permeability [12-15]. The synthetic methods for preparing sulfonated polyimides are achieved either by direct sulfonation of the parent polymers or by polymerization of sulfonated monomers. Up to now, very few results can be found in the literature for the direct sulfonation of polyimides because of difficulty in sulfonating polyimides with a stable structure or the resulting sufonated polyimides possessing undesirable properties such as poor stability. The widely reported SPIs were mainly synthesized from sulfonated monomer. Mercier et al. first synthesized a series of SPIs from 2,2'-benzidinedisulfonic acid (BDSA), 4,4'oxydianiline (ODA), and two types of dianhydrides, 1,4,5,8-naphthalenetetra carboxylic dianhydride (NTDA) and oxydiphthalic anhydride (ODPA), respectively [16]. They studied membrane properties such as swelling and conductivity [13], and stability in aqueous medium [17]. They found that the six-member ring SPIs derived from NTDA have superior chemical and thermal stability compared to the more common five-member ring SPIs from ODPA. Furthermore, to improve the hydrolysis stability and conductivity of the membranes, they also developed aromatic ether diamines having different amino-substituted positions or bulky groups in their structure and used them with NTDA and BDSA to synthesize several series of SPIs. But no better results had been achieved [18]. Litt et al. prepared a series of rigid and bulky or angled sulfonated copolyimides from NTDA, BDSA, and non-sulfonated diamines [19-21]. They reported that most membranes showed high proton conductivity (as high as $\mathrm{Nafion}^{\circledR}$ membranes at moderate relative humidity values and higher at high relative humidity levels). However, these membranes had poor hydrolysis stability and poor mechanical strength. Watanabe et al. also prepared a series of SPIs from NTDA, BDSA and different non-sulfonated diamine monomers such as 1,5-diaminonaphthalene (DAN)[22], 4,4'-(9-fluorenylidene) dianiline (FDA) [23], and 3,3'-bis(trifluoromethyl)benzidine (FMB) [24]. Their results indicated that these SPI membranes showed high proton conductivity, high mechanical and thermal stability, and good water stability. Winston Ho et al. synthesized the SPIs using NTDA, 4,4'-diaminostilbene-2,2'-disulfonic acid (DSDSA), and other three common diamines, i.e., 4,4'-oxydianline (ODA), 4,4'-methylene dianiline (MDA), and 4,4'-(9fluorenylidene) dianiline (FDA) [16]. The resulting SPI membranes showed good thermal stability and high conductivity at high relative humidity levels [25]. It is obvious that the SPIs with different non-sulfonated diamine moieties were widely studied. It is very important to investigate the effects of the non-sulfonated diamine structure on the properties of SPI membranes for development of high performance membranes. Hence, the development of new non-sulfonated diamines monomers is also strongly desired.

In this paper, we report the synthesis of a series of new naphthalenic SPI containing benzoxazole moieties using NTDA, BDSA, 1,10-diaminedecane (DADE) and 5amino-2-(p-aminophenyl)benzoxazole $(A B O)$ diamine. Through several experiments such as water swelling, proton conductivity, mechanical properties and thermal stability, the effects of incorporating benzoxazole unit in the polymer chain on the membrane's properties are discussed. 


\section{Results and discussion}

\section{Synthesis and characterization of monomer and polymers}

As shown in Scheme 1, the diamine monomer $A B O$ was synthesized from para aminobenzoic acid (PA) and 2,4-diamino-4-hydroxybenzene dihydrochloride in PAA. The chemical structure of the obtained diamine was confirmed by ${ }^{1} \mathrm{H}$ NMR and FT-IR spectrum. In the ${ }^{1} \mathrm{H}$ NMR spectrum of $A B O$, the absorption peaks at $4.98 \mathrm{ppm}$ and $5.86 \mathrm{ppm}$ are assigned to the protons of amino group. The signals in range of 6.56$7.78 \mathrm{ppm}$ are clearly assigned to the phenyl ring protons. The FT-IR spectrum was described in the Experimental section.

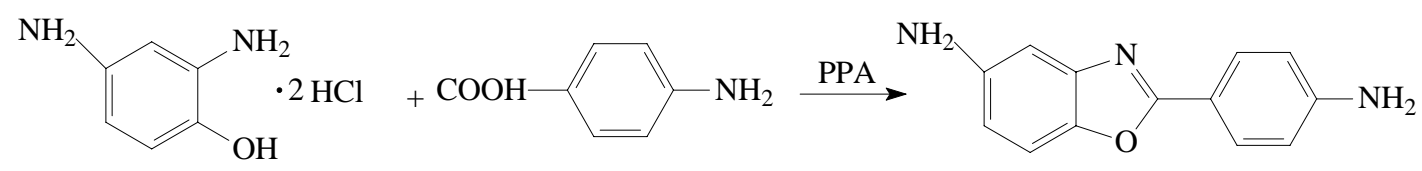

Scheme 1. Synthesis of $A B O$ monomer.

The preparation of the sulfonated polyimides, SPI-X, was carried out according to a one-step polymerization method using $m$-cresol as the solvent in the presence of triethylamine (TEA) and benzoic acid (as shown in Scheme 2). In this case TEA was employed to improve the solubility of BDSA by liberating the protonated amino groups and benzoic acid was used as an imidization catalyst [25]. The sulfonated degree of the SPI-X was easily controlled through varying the molar ratio of BDSA to the non-sulfonated diamines. Tough, transparent and flexible membranes, with the typical polyimide brown color, were obtained by casting from the polymer solution. The obtained SPI-X membranes in triethylamine salt form were proton-exchanged with $1 \mathrm{M} \mathrm{HNO}_{3}$ solution at room temperature.

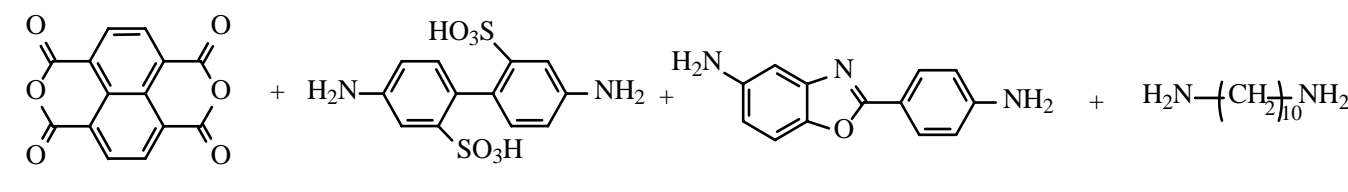

NTDA

BDSA

$\mathrm{ABO}$

DADE

\begin{tabular}{l|l}
$90^{\circ} \mathrm{C} / 4 \mathrm{~h}$ & $\mathrm{~m}$-Cresol \\
$180^{\circ} \mathrm{C} / 17 \mathrm{~h}$ & $\mathrm{Et}_{3} \mathrm{~N}$ \\
$195^{\circ} \mathrm{C} / 3 \mathrm{~h}$ & $\downarrow$ Benzoic acid
\end{tabular}

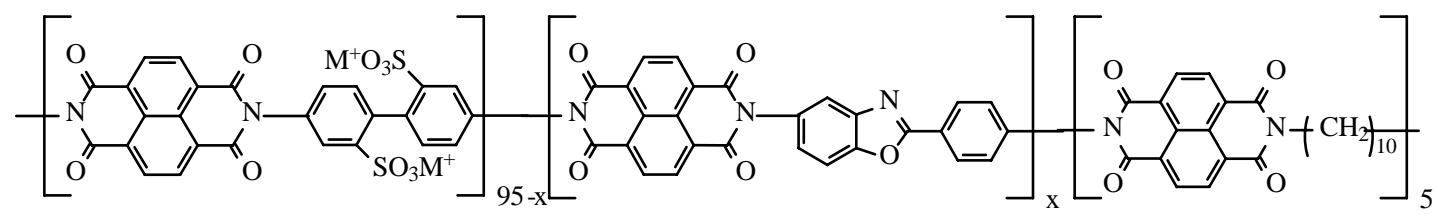

SPI-X

$\mathrm{M}^{+}={ }^{+} \mathrm{NH}\left(\mathrm{C}_{2} \mathrm{H}_{5}\right)_{3}$

Scheme 2. Synthesis of the new sulfonated polyimide copolymers.

The properties of SPI-X copolymers are summarized in Table 1. The IEC values obtained from titration were slightly smaller than the theoretical value, which might be 
caused by the incomplete imidization in the one-step polymerization process, the incomplete acidification as well as incomplete drying of the membranes. The IEC value of the SPI-X membranes increased from $2.17 \mathrm{mmol} / \mathrm{g}$ to $2.81 \mathrm{mmol} / \mathrm{g}$ with the decrease of the ABO amount from $30 \mathrm{~mol} \%$ to $10 \mathrm{~mol} \%$ due to the introduction of more sulfonic acid groups. The reduced viscosities $\left(\eta_{r}\right)$ of the resultant polymers (triethylamine salt form) were measured at $38{ }^{\circ} \mathrm{C}$ in $\mathrm{m}$-cresol and ranged from 0.32 to $2.27 \mathrm{dl} / \mathrm{g}$. Though we could not directly determine the molecular weights of the polyimides by GPC due to the insolubility of the polyimides in N,N-dimethyl formamide(DMF), the fiber-like precipitates obtained by pouring the polymer solutions into acetone and the tough films formed by solution casting suggest that the high molecular weight polyimides were obtained.

The solubility behaviors of the SPI-X in triethylamine salt form are shown in Table 2 . All the sulfonated polyimides in triethylamine salt form were soluble in $m$-cresol and dimethyl sulfoxide (DMSO), but insoluble or partially soluble in other common polar aprotic solvents such as 1-methylpyrrolidone (NMP), N,N-dimethylformamide (DMF) and N,N-dimethylacetamide (DMAC).

Tab. 1. Properties of the sulfonated polyimide copolymers.

\begin{tabular}{|c|c|c|c|c|c|c|c|}
\hline \multirow{2}{*}{ SPI-X } & \multicolumn{3}{|c|}{ Monomer ratio (mol\%) } & \multirow{2}{*}{$\begin{array}{c}\eta_{r}^{a} \\
\text { in } \mathrm{dL} / \mathrm{g}\end{array}$} & \multirow{2}{*}{$\begin{array}{c}E W \\
\text { in } \mathrm{g} / \mathrm{mmol}\end{array}$} & \multicolumn{2}{|c|}{ IEC in $\mathrm{mmol} / \mathrm{g}$} \\
\hline & $\mathrm{ABO}$ & BDSA & DADE & & & Calc. $^{\mathrm{b}}$ & Expt. $^{\mathrm{C}}$ \\
\hline SPI- 0 & 0 & 95 & 5 & 0.33 & $-{ }^{d}$ & 3.35 & - \\
\hline SPI-10 & 10 & 85 & 5 & 0.32 & 356 & 3.06 & 2.81 \\
\hline SPI-20 & 20 & 75 & 5 & 2.27 & 386 & 2.76 & 2.59 \\
\hline SPI-30 & 30 & 55 & 5 & 1.97 & 407 & 2.46 & 2.17 \\
\hline
\end{tabular}

${ }^{\mathrm{a}} 0.1 \mathrm{~g} / \mathrm{dL}$ in $\mathrm{m}$-cresol at $38^{\circ} \mathrm{C}$.

${ }^{\mathrm{b}}$ Calculated from the feed monomer ratio.

${ }^{c}$ Estimated from the titration method.

${ }^{\mathrm{d}}$ Not measured.

Tab. 2. Solubility behavior of the sulfonated polyimide copolymers in triethylamine salt form.

\begin{tabular}{cccccc}
\hline SPI-X & m-Cresol & DMSO & DMF & NMP & DMAC \\
\hline SPI-0 & $+^{a}$ & $+^{b}$ & + & $+{ }^{c}$ & +- \\
SPI-10 & ++ & + & +- & +- & $-{ }^{d}$ \\
SPI-20 & + & + & +- & +- & - \\
SPI-30 & + & + & - & - & - \\
\hline
\end{tabular}

a "++" soluble at room temperature.

b "+" soluble at elevated temperature.

c "+-" partially soluble.

d "-" insoluble.

The FT-IR spectra of sulfonated polyimide in triethylamine salt form are shown in Figure 1. Typical absorption bands for naphthalene imido rings are observed at $1717 \mathrm{~cm}^{-1}$ (C=O symmetric), $1674 \mathrm{~cm}^{-1}$ ( $\mathrm{C}=\mathrm{O}$ asymmetric) and $1347 \mathrm{~cm}^{-1}$ (C-N stretching), respectively. The absorption bands of the sulfonic acid groups are around $1024 \mathrm{~cm}^{-1}\left(\mathrm{~S}=\mathrm{O}\right.$ symmetric) and $1083 \mathrm{~cm}^{-1}(\mathrm{~S}=\mathrm{O}$ asymmetric $)$, respectively. The characteristic absorption bands of benzoxazole are around $1628 \mathrm{~cm}^{-1}(\mathrm{C}=\mathrm{N}$ 
stretching) and $1050 \mathrm{~cm}^{-1}$ (C-O stretching), respectively. The absorption band of benzoxazole around $1050 \mathrm{~cm}^{-1}$ is not clear, which is because of the overlap with the characteristic band of sulfonic acid group around $1024 \mathrm{~cm}^{-1}$. The absorption band at $1582 \mathrm{~cm}^{-1}$ should be assigned to the stretch vibration of benzene ring $(C=C)$.

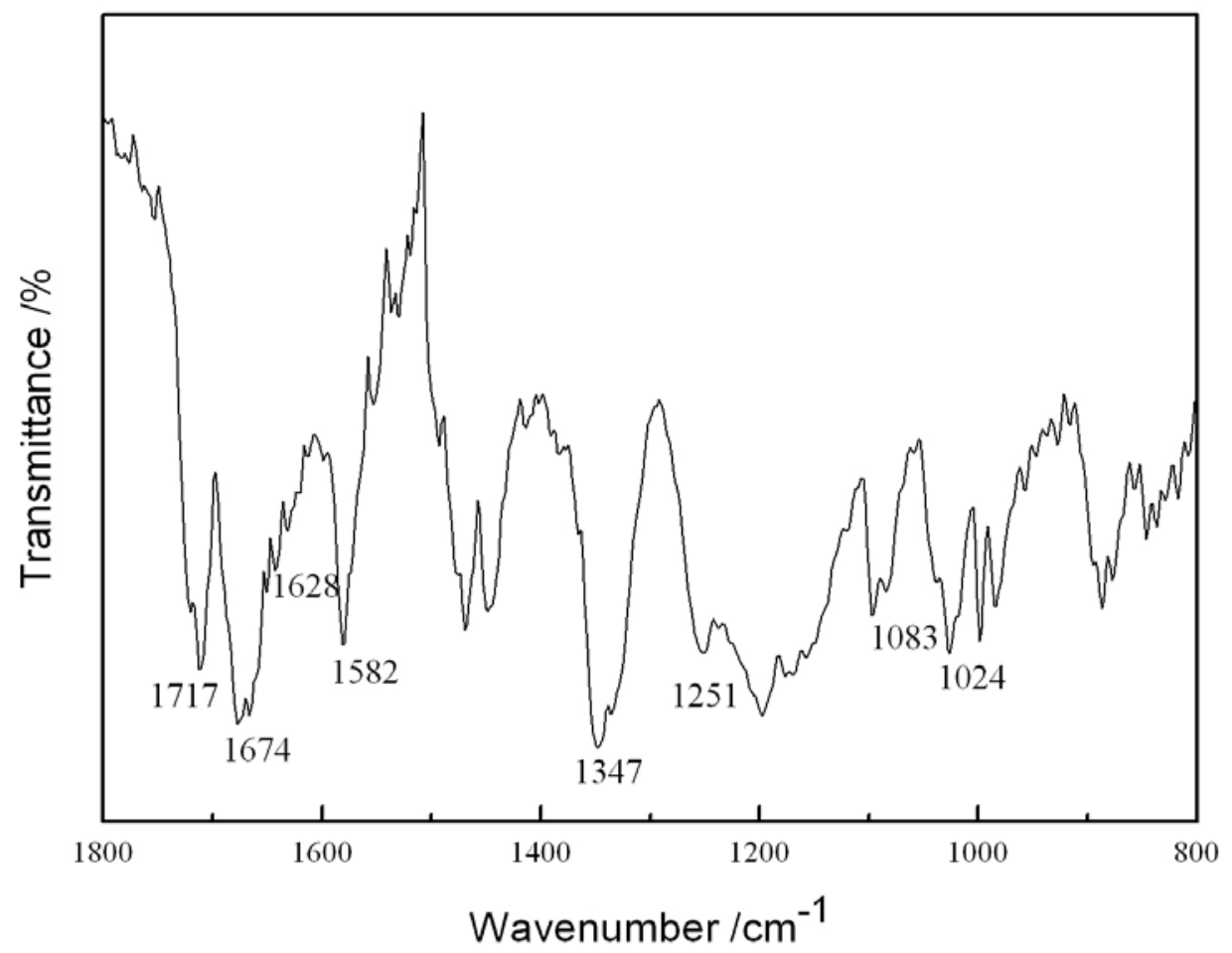

Fig. 1. FT-IR spectrum of the sulfonated polyimide copolymer (SPI-20).

\section{Thermal properties of SPI-X}

Thermal stability of the new SPI copolymers, which were completely dried in a vacuum oven at $150{ }^{\circ} \mathrm{C}$ overnight before measurements, was investigated by TGA measurements. For comparison, the TGA curve of undried SPI-20 was also measured at the same conditions. Figure 2 shows the TGA curves of the sulfonated polyimides in triethylamine salt form. In these curves three-step weight loss was observed, and the onset temperature for the second and the third degradation steps was given in Table 3. The initial weight loss before $150{ }^{\circ} \mathrm{C}$ was caused by the desorption of the sorbed water within the sample. The weight loss increased from $2.91 \%$ to $6.24 \%$ with the increase of the sulfonated degree due to more bonded water to sulfonic acid groups. For undried SPI-20 copolymers, similar observations were obtained and the weight loss was more than that of the thermal treated SPI-20 copolymers, which related to the desorption of more moisture in the sample. The second step started from around $272{ }^{\circ} \mathrm{C}$ was attributed to the decomposition of sulfonic acid groups. As the degree of sulfonation increased, the weight loss at the same temperature increased or the degradation temperatures decreased for the same weight losses. The third step of degradation around $517{ }^{\circ} \mathrm{C}$ was assigned to the decomposition of the polyimide backbone. Furthermore, the higher ABO contents resulted in more final residues at $550{ }^{\circ} \mathrm{C}$. These results clearly indicate that the new SPI copolymers have fairly good thermal stabilities. 


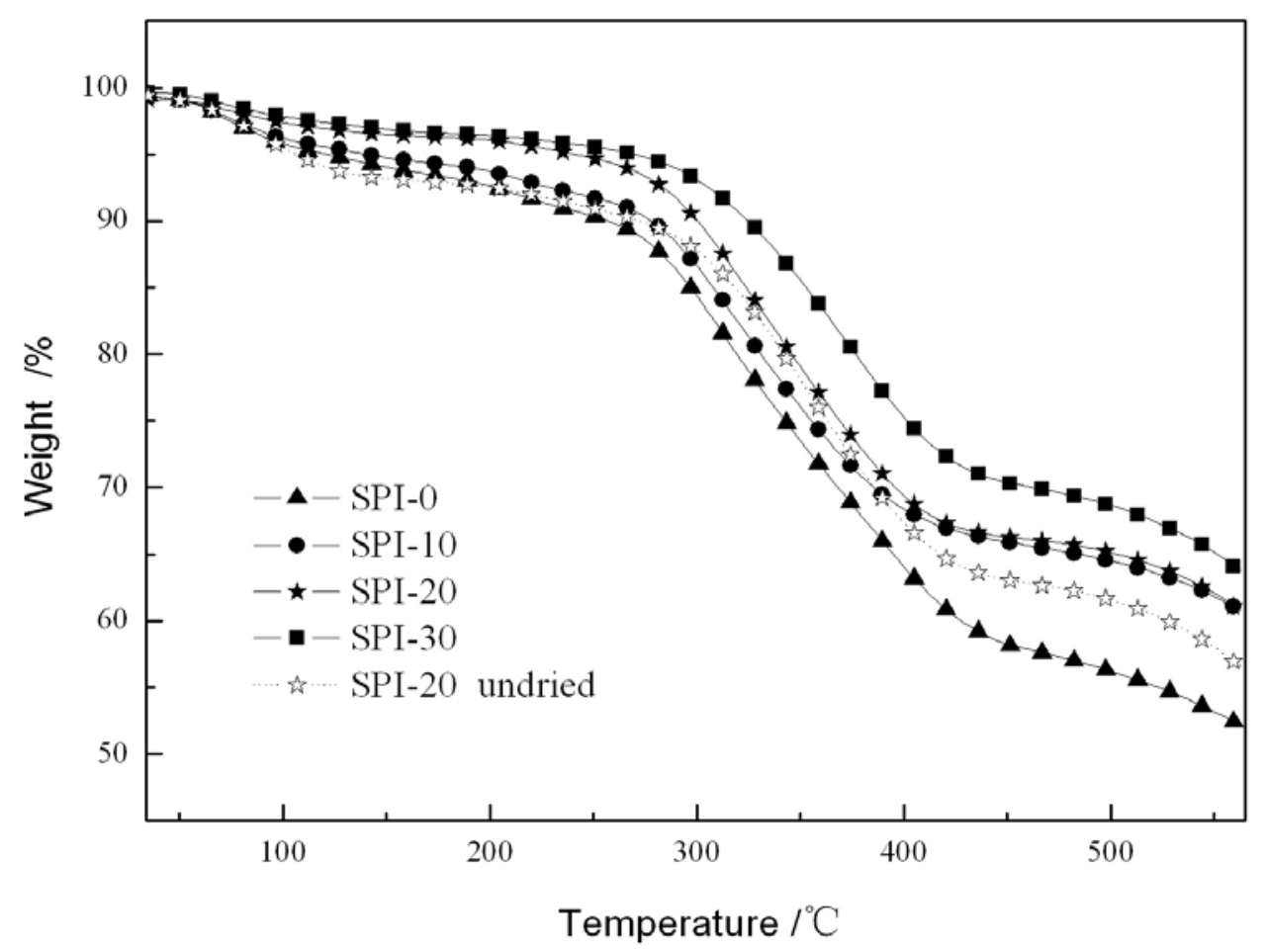

Fig. 2. TGA curves of the new sulfonated polyimide copolymers.

Tab. 3. Thermal properties of sulfonated polyimide copolymers.

\begin{tabular}{|c|c|c|c|c|}
\hline \multirow[b]{2}{*}{ Membranes } & \multirow[b]{2}{*}{$\begin{array}{l}\text { Initial weight loss } \\
\text { before } 150 \text { in \% }\end{array}$} & \multicolumn{2}{|c|}{ Onset temperature in ${ }^{\circ} \mathrm{C}$} & \multirow{2}{*}{$\begin{array}{c}\text { Residues } \\
\text { at } 550^{\circ} \mathrm{C} \\
\text { in } \%\end{array}$} \\
\hline & & $\begin{array}{c}\text { Second } \\
\text { decomposition }\end{array}$ & $\begin{array}{c}\text { Third } \\
\text { decomposition }\end{array}$ & \\
\hline SPI-0 & 6.24 & 272 & 517 & 53.06 \\
\hline SPI-10 & 5.32 & 272 & 517 & 61.71 \\
\hline SPI-20 & 3.65 & 274 & 511 & 61.93 \\
\hline SPI-30 & 2.91 & 283 & 517 & 65.28 \\
\hline SPI-20ND ${ }^{a}$ & 6.87 & 275 & 513 & 57.73 \\
\hline
\end{tabular}

${ }^{a}$ Undried SPI-20 copolymer.

\section{Water uptake and swelling ratio of SPI-X membranes}

The water content in membrane is important for fuel cell applications since this affects their mechanical properties and the transport of protons, but too much water absorption results in excessive swelling, mechanical fragility and morphological instability of the membrane. Generally, higher IEC shows higher water uptake, because the introduction of sulfonic acid group makes the polymer membranes hydrophilic. As shown in Table 4, the water uptake of SPI-X membranes increased from $53.0 \mathrm{wt} \%$ to $106.9 \mathrm{wt} \%$ with the increase of sulfonated degree. The water uptake showed its minimum of $53.0 \mathrm{wt} \%$ at $\mathrm{X}=30($ IEC $=2.17 \mathrm{mmol} / \mathrm{g})$ despite the enhanced hydrophobicity, which was still higher than that of Nafion ${ }^{\circledR} 117$ membrane $(31.8 \mathrm{wt} \%)$. Furthermore, the number of absorbed water molecules per sulfonic acid group $(\lambda)$ of SPI-X increased from 14 to 21 with the increase of sulfonated degree. 
The size changes in length and width dimension of SPI membranes did not show much variability. However, the SPI membranes showed highly anisotropic swelling ratio in thickness and plane dimension, that is, much larger swelling ratio in membrane thickness direction than in plane direction. For instance, the SPI-20 membrane showed 3 times larger swelling in thickness direction (14.8\%) than in length direction (4.7\%). The anisotropic membrane swelling is considered due to the polymer chain alignment in plane direction. The rigid imide backbone from NTDA and benzoxazole-diamine seemed to cause the better alignment in plane direction.

Tab. 4. Water uptake and swelling ratio of SPI-X and Nafion ${ }^{\circledR} 117$ membranes.

\begin{tabular}{ccccccc}
\hline Membranes & $\begin{array}{c}\text { IEC } \\
\text { in mmol/g }\end{array}$ & $\begin{array}{c}\text { Water uptake } \\
\text { in wt\% }\end{array}$ & $\begin{array}{c}\lambda \\
\left(\mathrm{H}_{2} \mathrm{O} / \mathrm{SO}_{3} \mathrm{H}\right)\end{array}$ & \multicolumn{3}{c}{ Swelling ratio In \% } \\
\cline { 5 - 7 } & 2.81 & 106.9 & 21 & 17.1 & 10.2 & 9.7 \\
SPI-10 & 2.59 & 64.5 & 14 & 14.8 & 4.7 & 4.3 \\
$\mathrm{SPI}-20$ & 2.17 & 53.0 & 14 & 9.5 & 3.0 & 3.2 \\
$\mathrm{SPI}-30$ & 0.86 & 31.8 & 21 & 18.9 & 19.6 & 19.0 \\
Nafion $^{\circledR} 117$ & & & & & &
\end{tabular}

${ }^{\mathrm{a}}$ Swelling ratio in thickness dimension

${ }^{\mathrm{b}}$ Swelling ratio in length dimension

${ }^{c}$ Swelling ratio in width dimension

\section{Mechanical properties and oxidative stability}

The mechanical properties of SPI membranes are an important factor affecting membrane performance. The mechanical properties of SPI membranes were evaluated by means of tensile strength. As a reference, Nafion ${ }^{\circledR} 117$ membrane was also subjected to the testing at $85{ }^{\circ} \mathrm{C}$ and $93 \% \mathrm{RH}$. The test results of SPI and Nafion ${ }^{\circledR} 117$ membranes are summarized in Table 5 . Nafion ${ }^{\circledR} 117$ showed a large elongation up to $330 \%$ with the maximum stress of $23 \mathrm{MPa}$ at break. While the SPI20 membrane displayed higher strength with the maximum stress at break of $42 \mathrm{MPa}$ and the elongation at break of merely $5.1 \%$. This small strain is advantageous since the MEA should display little changes in its size under fuel cell operating conditions. It was indicated that SPI membranes containing benzoxazole moieties had high mechanical stabilities due to its rigid molecular structure which could suppress the elongation of the membrane.

Tab. 5. Mechanical properties and oxidative stability of SPI-X and Nafion ${ }^{\circledR} 117$.

\begin{tabular}{cccc}
\hline Polymers & $\begin{array}{c}\text { Maximum stress } \\
\text { in MPa }\end{array}$ & $\begin{array}{c}\text { Maximum strain } \\
\text { in \% }\end{array}$ & $\begin{array}{c}\text { Oxidative stability } \\
\text { in min }\end{array}$ \\
\hline SPI-10 & 26 & 8.5 & 15 \\
SPI-20 & 42 & 5.1 & 96 \\
SPI-30 & 45 & 3.7 & 130 \\
Nafion ${ }^{\circledR} 117$ & 23 & 330 & - \\
\hline
\end{tabular}

The oxidative stability of SPI-X membranes $(20 \mu \mathrm{m})$ was examined by observing the dissolving behavior in Fenton's reagent at $80{ }^{\circ} \mathrm{C}$ as an accelerated testing (Table 4). Since the oxidative species such as $\mathrm{HO}$ and $\mathrm{HOO}$ accompany some water molecules when reacting to the substances, the oxidative stability of SPI-X was 
improved as increasing in the hydrophobic group $A B O$ content. The polyimide membrane with $\mathrm{X}=30$ had good oxidative stability, enduring for more than $2 \mathrm{~h}$ in Fenton's reagent at $80^{\circ} \mathrm{C}$.

\section{Proton conductivity}

The proton conductivity in thickness direction of SPI-X membranes was measured as a function of temperature, as shown in Figure 3. Prior to measurements, all membrane samples were soaked in water for $48 \mathrm{~h}$ at room temperature for hydration. The proton conductivities of the SPI-X increased with the increase of the sulfonated degrees. The SPI-20 showed a proton conductivity of $6.2 \times 10^{-3} \mathrm{~S} / \mathrm{cm}$ at $30^{\circ} \mathrm{C}$, which was close to that of Nafion ${ }^{\circledR} 117$ membrane measured under the same conditions $\left(9.8 \times 10^{-3} \mathrm{~S} / \mathrm{cm}\right)$. The relatively low conductivity would be due to the lack of properly connected hydrophilic channels for the proton conduction compared to the perfluorinated ionomers. It is a common behavior observed for hydrocarbon-based ionomers [1].

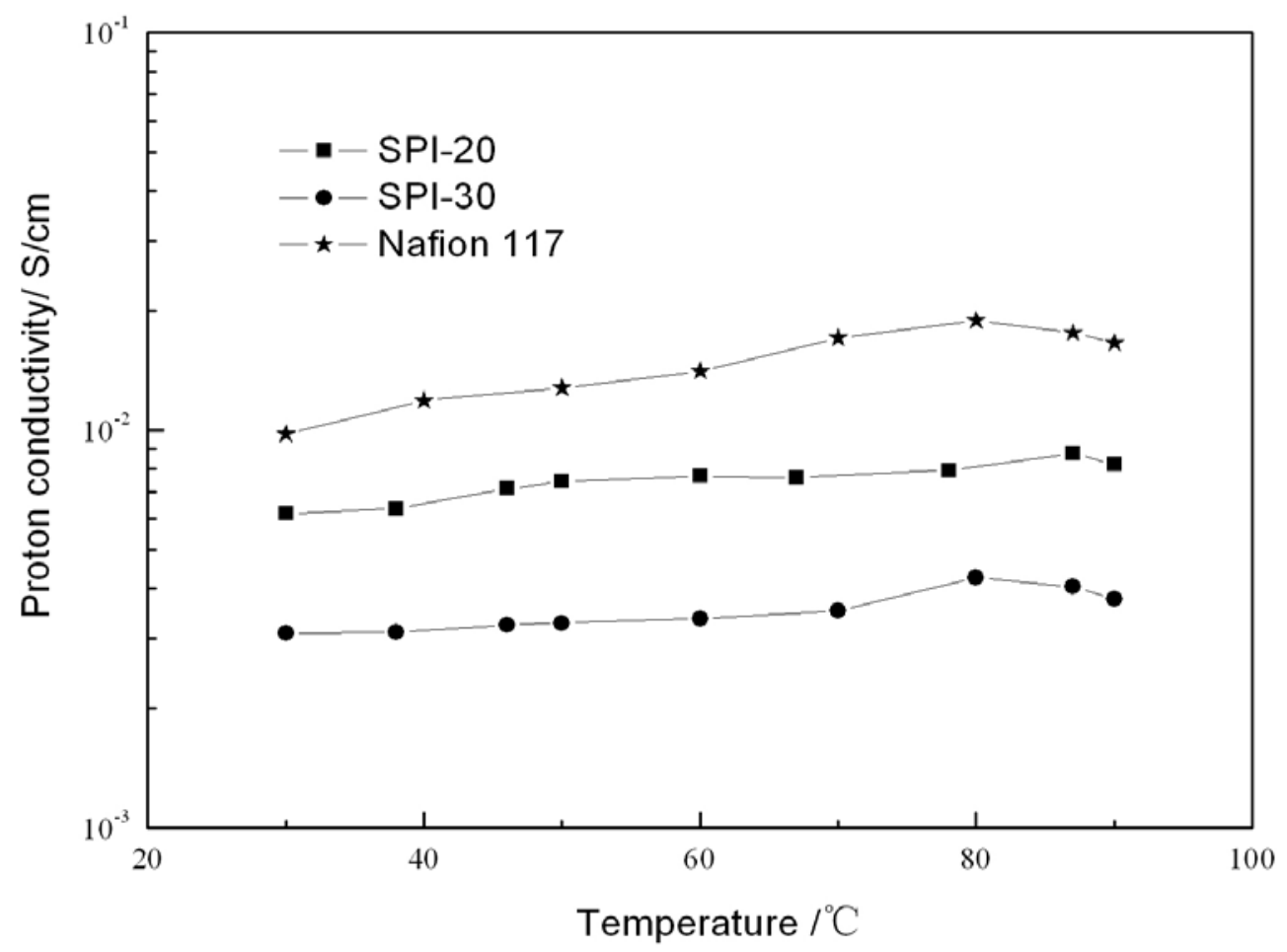

Fig. 3. The effect of temperature on the proton conductivities of SPI-X membranes and Nafion ${ }^{\circledR} 117$ membrane.

As the proton conductivity is thermally motivated in general, it is natural for proton conductivity to increase with the increase of temperature. On the other hand, the decrease of the proton conductivity above a certain temperature suggests the dehydration of the SPI-X membrane at high temperature. Therefore, the water content and temperature are two competing trends. That is, at low temperature, the effect of dehydration on proton conductivity may be negligible compared with that of temperature; however, at high temperature, the effect of dehydration, which may even play the dominant role during the measurements, on proton conductivity cannot 
be neglected. Thus, there is generally a turning point in each conductivity curve. The turning point is different for different membranes. Generally, SPI-X membranes with the more sulfonic acid groups start to lose conductivity at higher temperature due to their stronger ability of retaining water. The effect of temperature on the proton conductivities of SPI-X membranes and Nafion ${ }^{\circledR} 117$ membrane are shown in Figure 3 . The proton conductivity of SPI-20 membrane increased with the temperature increasing up to $8.8 \times 10^{-3} \mathrm{~S} / \mathrm{cm}$ at $87^{\circ} \mathrm{C}$, then decreased. The SPI-30 membrane, however, lost water so fast that its conductivity began to decrease at $80^{\circ} \mathrm{C}$.

The proton conductivity in plane direction of SPI-20 membrane was also measured, and it was nearly one order of magnitude higher than that in thickness direction under the same conditions, as shown in Figure 4. The proton conductivity in plane direction of SPI-20 membrane displayed a monotonous increase at all range of measurement temperature and reached to $2.56 \times 10^{-2} \mathrm{~S} / \mathrm{cm}$ at $90{ }^{\circ} \mathrm{C}$. This result suggests that bulk properties of the SPI membranes differ from that of surface. In the accrual fuel cell, protons migrate through the PEM in the thickness direction, so the measurement technique in the thickness direction is perhaps the most appropriate for the membranes intended for fuel cell applications.

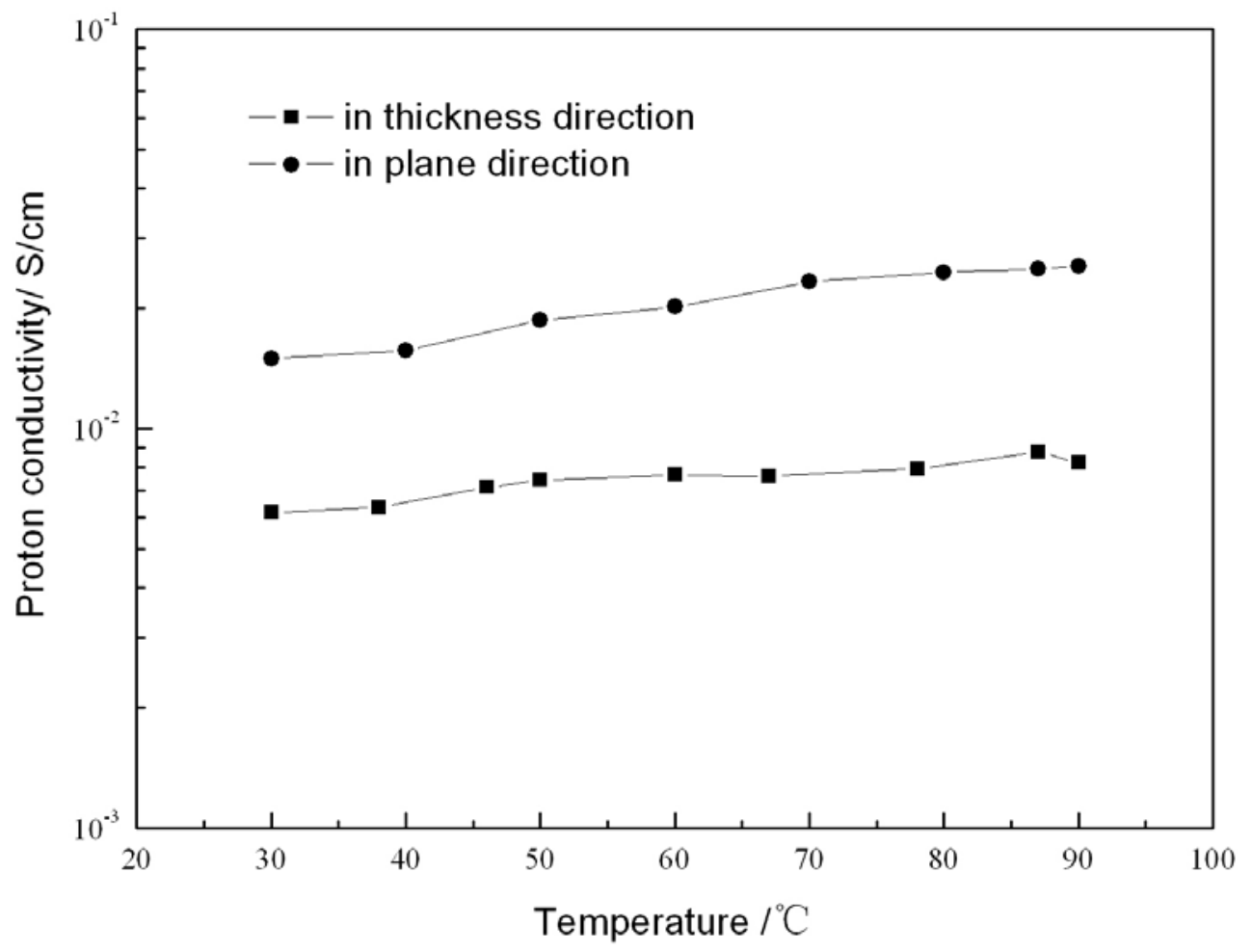

Fig. 4. The effect of temperature on the proton conductivities of SPI-20 membrane in thickness and plane direction.

\section{Conclusions}

A series of new sulfonated polyimides containing benzoxazole moieties were synthesized to evaluate the effects of the benzoxazole content on their properties. Tough and transparent membranes were obtained by casting from the polymer solution. They showed higher water uptake, lower swelling ratio and better mechanical stability in comparison with Nafion ${ }^{\circledR} 117$. The resultant polyimides were 
thermally stable, with a decomposition temperature of $272{ }^{\circ} \mathrm{C}$. The stability in Fenton's reagent was measured to show that the introduction of benzoxazole moieties improved the oxidative stability. The proton conductivity of SPI membrane containing $20 \mathrm{~mol} \%$ benzoxazole moieties was comparable to that of Nafion ${ }^{\circledR} 117$ membrane. The conductivities in thickness and plane direction were clearly anisotropic, with much higher proton conductivity in plane direction than that in thickness direction. These preliminary results have proved its potential availability as proton exchange membrane for PEMFC.

\section{Experimental part}

\section{Materials and measurements}

1,4,5,8-naphthalenetetracarboxylic dianhydride (NTDA) and 2,2'-benzidinedisulfonic acid (BDSA) were purchased from Tokyo Kasei Co. and was purified by vacuo sublimation prior to use. 1,10-diaminedecane (DADE) was purchased from Acros Organics and used as received. 2,4-diaminophenol dihydrochloride (DADH) was purchased from Alfa Aesar Co. and was recrystallized from $3.5 \mathrm{~mol} / \mathrm{L}$ hydrochloric acid prior to use. Triethylamine (TEA) were purified by distillation under reduced pressure and dehydrated with $3 \AA$ molecular sieves (Aldrich) prior to use. m-Cresol was also dried over $3 \AA$ molecular sieves prior to use. Ultra-pure water was obtained from a Millipore Milli-Q purification system. Other chemicals were of commercial grade and used as received unless otherwise mentioned.

FT-IR spectra were measured on a Thermo Nicolet Nexus 670 Fourier transform spectrometer with powder samples in air. ${ }^{1} \mathrm{H}$ NMR spectra were performed on a Bruker Avance 400 spectrometer operation at $399.95 \mathrm{MHz}$ in DMSO- $d_{6}$. Reduced viscosities $\left(\eta_{r}\right)$ of the samples were measured using an Ubbelohde viscosimeter at a concentration of $0.1 \mathrm{~g} / \mathrm{dl}$ in $\mathrm{m}$-cresol solution at $38^{\circ} \mathrm{C}$. Thermo gravimetric analysis (TGA) was carried out by Netzsch STA 449 thermal analysis system at a heating rate of $10^{\circ} \mathrm{C} / \mathrm{min}$ under argon atmosphere.

\section{Synthesis of monomer $(A B O)$}

In the preparation, $0.05 \mathrm{~mol}$ of para aminobenzoic acid (PA), $0.05 \mathrm{~mol}$ of DADH, and $0.3 \mathrm{~g}$ of $\mathrm{SnCl}_{2}$ were dissolved in polyphosphoric acid (PAA) with continuous stirring under nitrogen flow. The mixture was heated up to $110{ }^{\circ} \mathrm{C}$ in order to remove the hydrochloride, using $\mathrm{AgNO}_{3}$ as indicator. The reaction solution was then slowly reheated up to $190^{\circ} \mathrm{C}$ and lasted for $6 \mathrm{~h}$.<smiles>[H][Y]c1cccc(-c2nc3ccc([2H])c([2H])c3o2)c1</smiles>

Fig. 5. The chemical structure of $A B O$ monomer. 
After cooling to room temperature, the mixture was poured into the $50 \%$ sodium carbonate solution, the slightly yellow product was obtained and repeatedly washed with water until the $\mathrm{pH}$ value was approximately $6 \sim 7$, centrifugal sedimentation, the precipitate was filtered and dried. The chemical structure of $A B O$ monomer is shown in Figure 5. The obtained crude product was recrystallized from methanol to give slightly yellow solid product, which was dried in vacuo (Yield: 71\%). m.p.(DSC): $239.5^{0} \mathrm{C}$. FT-IR $\left(\mathrm{KBr}, \mathrm{cm}^{-1}\right)$ : 3395, 3322, 3197, 1646, 1604, 1597, 1557, 1496, 1451 , 1440, 1270, 1059, 927, 853, 836, 740, 701, 619. ${ }^{1} \mathrm{H}$ NMR (DMSO-d 6 , ס): 7.78-7.80(d, $2 \mathrm{H}), 7.27-7.30(\mathrm{~d}, 1 \mathrm{H}), 6.77-6.78(\mathrm{~d}, 1 \mathrm{H}), 6.65-6.67(\mathrm{~d}, 2 \mathrm{H}), 6.53-6.56(\mathrm{q}, 1 \mathrm{H}), 4.98$ (s, $2 \mathrm{H}), 5.68(\mathrm{~s}, 2 \mathrm{H})$.

\section{Synthesis of polymers}

Sulfonated polyimide copolymers SPI-X (where $X$ refers to the molar percentage of $A B O$ content) with $X$ from 0 to $30 \mathrm{~mol} \%$ were synthesized from NTDA, ABO, DADE and BDSA. A typical procedure for preparation of sulfonated polyimide copolymers was described below using SPI-20 as an example. In the preparation, $1.032 \mathrm{~g}$ (3.0 $\mathrm{mmol})$ of BDSA, $0.18 \mathrm{~g}(0.8 \mathrm{mmol})$ of $A B O, 18 \mathrm{ml}$ of $\mathrm{m}$-cresol, and $0.86 \mathrm{ml}$ of triethylamine, were placed in a $100 \mathrm{ml}$ completely dried four-neck round bottomed flask equipped with a reflux condenser, mechanical stirring device, thermometer and nitrogen inlet. The suspension was stirred at $70{ }^{\circ} \mathrm{C}$ for $0.5 \mathrm{~h}$ under nitrogen flow. After clear solution was obtained, $1.072 \mathrm{~g}(4 \mathrm{mmol})$ of NTDA, $0.0344 \mathrm{~g}(0.2 \mathrm{mmol})$ of DADE, $1.954 \mathrm{~g}(16 \mathrm{mmol})$ of benzoic acid and $30 \mathrm{ml}$ of $\mathrm{m}$-cresol were added to the flask. The polymerization was carried out at $80{ }^{\circ} \mathrm{C}$ for $4 \mathrm{~h}$, then $180{ }^{\circ} \mathrm{C}$ for $17 \mathrm{~h}$ and $195{ }^{0} \mathrm{C}$ for $3 \mathrm{~h}$ to obtain a dark brown viscous solution. The solution was poured into large excess of acetone with vigorous stirring and the precipitate was filtered off and washed thoroughly with acetone. The resulting gray brown fiber-like copolymer was collected after drying at $120{ }^{\circ} \mathrm{C}$ in vacuum overnight. The polyimide copolymers in triethylamine salt form were obtained (yield: 92\%).

\section{Membrane preparation}

The resulting SPI-X in triethylamine salt form was dissolved in $\mathrm{m}$-cresol to make a 10 wt \% solution. The filtered solution was cast onto a glass plate and dried at $80{ }^{\circ} \mathrm{C}{ }^{\circ} \mathrm{C}$ under atmospheric pressure for $6 \mathrm{~h}$ and under reduced pressure for $12 \mathrm{~h}$. The residual solvent was further evaporated at $150{ }^{\circ} \mathrm{C}$ under vacuum for $24 \mathrm{~h}$, after cooling down to room temperature. It resulted in brown and tough membrane films. The obtained crude membrane in triethylamine salt form was soaked in ethanol containing $1 \mathrm{M} \mathrm{HNO}_{3}$ at room temperature for $24 \mathrm{~h}$ and subsequently rinsed with deionized water several times until the $\mathrm{pH}$ value was approximately 6 7, and then dried at $60{ }^{\circ} \mathrm{C}$ for $24 \mathrm{~h}$ under reduced pressure.

\section{Determination of the ion exchange capacity (IEC)}

The IEC values of the sulfonated polyimides were experimentally determined by titration. The films were weighed and then soaked in $1 \mathrm{M} \mathrm{NaCl}$ saturated solution for $24 \mathrm{~h}$ in order to extract the protons from the membrane. The solution was then neutralized using a dilute $\mathrm{NaOH}$ solution of known concentration. The IEC values were calculated from the moles of $\mathrm{NaOH}$ used divided by the mass of the sample according to Eq. (1)

$I E C=\left(V_{\mathrm{NaOH}} \times C_{\mathrm{NaOH}}\right) / M_{\text {simple }}$ 
where $V_{\mathrm{NaOH}}$ is the volume of $\mathrm{NaOH}$ that was titrated, $\mathrm{C}_{\mathrm{NaOH}}$ is the concentration of $\mathrm{NaOH}$ that was titrated, and Msample is the mass of the polymer sample.

\section{Water uptake and swelling ratio}

All the polymer membranes were vacuum dried at $100{ }^{0} \mathrm{C}$ for $24 \mathrm{~h}$ before testing. Water uptake was measured by immersing three sheets of films of polyimide into deionized water at room temperature for $48 \mathrm{~h}$. Then the films were taken out, wiped with tissue paper, and quickly weighed on a microbalance. The water uptake (WU) of the films was calculated according to Eq. (2)

$W U=\left(G_{w}-G_{d}\right) / G_{d} \times 100 \%$

where, $G_{w}$ and $G_{d}$ are the weights of the wet and dry membranes, respectively. Water uptake of the polyimide membrane was estimated from the average value of $W U$ of each sheet.

Swelling ratio in thickness, length and width direction of SPI membranes were investigated by immersing more than two sample sheets in deionized water for $4 \mathrm{~h}$ at $80{ }^{\circ} \mathrm{C}$. The swelling ratio was calculated according to Eq. (3)

$\Delta t=\left(t-t_{\mathrm{d}}\right) / t_{\mathrm{d}} \times 100 \%$

$\Delta I=\left(I-I_{\mathrm{d}}\right) / I_{\mathrm{d}} \times 100 \%$

$\Delta w=\left(w-w_{\mathrm{d}}\right) / w_{\mathrm{d}} \times 100 \%$

where $t_{\mathrm{d}}, I_{\mathrm{d}}$ and $w_{\mathrm{d}}$ are the thickness, length and width of the dry membranes, respectively; $t$, I and $w$ refer to those of the membrane immersed in water.

\section{Mechanical properties and Oxidative stability}

Mechanical tensile testing was performed with an Instron Model 5569 instrument at $85{ }^{\circ} \mathrm{C}$ and $93 \% \mathrm{RH}$ at a crosshead speed of $10 \mathrm{~mm} / \mathrm{min}$. The membranes were cut into a dumbbell shape $(35 \times 16 \mathrm{~mm}$ (total area) and $25 \times 10 \mathrm{~mm}$ (test area)). A small piece of membrane samples with a thickness of $20 \mu \mathrm{m}$ was soaked in Fenton's reagent $\left(3.0 \% \mathrm{H}_{2} \mathrm{O}_{2}\right.$ aqueous solution containing $\left.2.0 \mathrm{ppm} \mathrm{FeSO}_{4}\right)$ at $80{ }^{0} \mathrm{C}$. The oxidative stability was evaluated by recording the time when membrane dissolved completely.

\section{Proton conductivity}

Proton conductivities of membranes were measured in thickness and plane direction by means of AC impedance spectroscopy using an EG\&G PARC Potentiostat/Galvanostat M273 over the frequency range of $100 \mathrm{kHz}$ to $1 \mathrm{~Hz}$. As shown in Figure 6(a), the conductivity in thickness direction was measured by sandwiching the membrane sample between two blocking stainless steel electrodes with diameter of $1.0 \mathrm{~cm}$. The measurement cell was mounted in a Tefolon cell case. The cell was placed in Ultra-pure water to measure the temperature dependence of proton conductivity. The conductivity $(\sigma)$ of the samples was calculated according to Eq. (4)

$\sigma=L / R \cdot S$ 
where $\sigma$ is the proton conductivity, $L$ and $S$ are the thickness and face area of the sample, respectively, and $R$ was resistance value measured. The measurements in plane direction were performed by the measurement device with open area and stainless steel electrodes (Figure 6(b)).

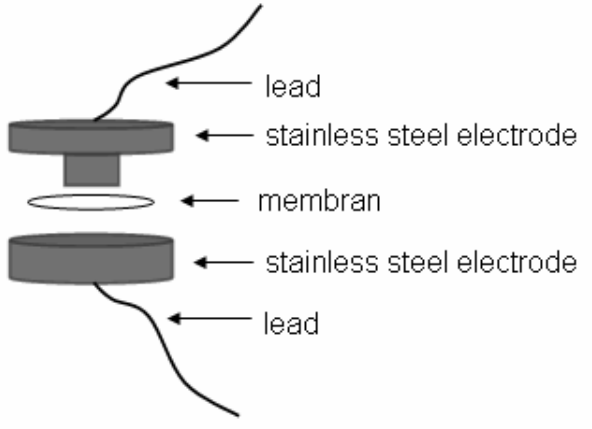

(a)

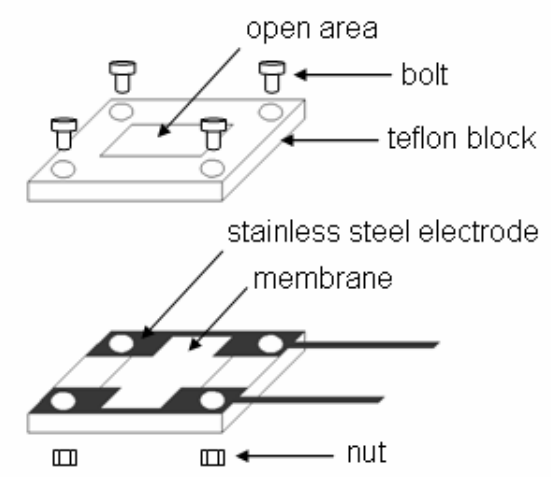

(b)

Fig. 6. Cells used for measuring membrane proton conductivity: (a) Cell for measurement in thickness direction; (b) Cell for measurement in plane direction.

\section{References}

[1] Kreuer, K. D. J. Membr. Sci. 2001, 185, 29.

[2] Hickner, M.; Ghassemi, H.; Kim, Y. S.; Einsla, B. R.; McGrath, J. E. Chem. Rev. 2004, 104, 4587.

[3] Li, L.; Zhang, J.; Wang, Y. X. J. Membr. Sci. 2003, 226, 159.

[4] Xing, P. X.; Robertson, G. P. J. Membr. Sci. 2004, 229, 95.

[5] Mikhailenko, S. D.; Wang, K. P.; Kaliaguine, S.; Xing, P. X.; Robertson, G. P.; Guiver, M. D. J. Membr. Sci. 2004, 233, 93.

[6] Jones, D. J.; Roziere, J. J. Membr. Sci. 2001, 185, 41.

[7] Zhang, X. P.; Liu, S. Z.; Liu, L. F.; Yin, J. Polymer 2005, 46, 1719.

[8] Ghassemi, H.; Ndip, G.; McGrath, J. E. Polymer 2004, 45, 5855.

[9] Kim, Y. S.; Wang, F.; Hickner, M.; Zawodzinski, T. A. J. Membr. Sci. 2003, 212, 263.

[10] Pu, H. T.; Liu, Q. Z.; Liu, G. H. J. Membr. Sci. 2004, 241, 167.

[11] Bae, J. M.; Honma, I.; Murata, M.; Yamamoto, T.; Rikukawa, M.; Ogata, M. Solid State lonics 2002, 147, 189.

[12] Shobha, H. K.; Sankarapandian. M.; Glass, T. E.; McGrath, J. E. Polym. Prepr. 2000, 41, 1298.

[13] Genies, C.; Mercier, R.; Sillion, B.; Petiaud, R.; Cornet, N.; Gebel, G. Polymer 2001, 42, 5097.

[14] Gunduz, N.; McGrath, J. Polym. Prepr. 2000, 41, 182.

[15] Piroux, F.; Espuch, E; Mercier, R.; Pineri, M.; Gebel, G. J. Membr. Sci. 2002, 209, 241.

[16] Faure S., Cornet N., Gebel G., Mercier R., Pineri M., Sillion B.; In proceedings of the International Symposium on New Materials for Fuel Cell and Modern Battery Systems, 2nd, Montreal, 1997, 818.

[17] Cornet, N.; Diat, O.; Gebel, G.; Jousse, F.; Marsacq, D.; Mercier, R.; Pineri, M. J. New. Mater. Electrochem. Syst. 2000, 3, 33. 
[18] Genies, C.; Mercier, R.; Sillion, B.; Cornet, N.; Gebel, G.; Pineri, M. Polymer 2000, 42, 359.

[19] Zhang, Y.; Litt, M.; Savinell, R. F.; Wainright, J. S. Polym. Prepr. 1999, 40, 480.

[20] Zhang, Y.; Litt, M.; Savinell, R. F.; Wainright, J. S.; Vendramini, J. Polym. Prepr. 2000, 41, 1561.

[21] Kim, H. J.; Litt, M. Polym. Prepr. 2001, 42, 486.

[22] Miyatake, K.; Asano, N.; Watanabe, M. J. Polym. Sci., Part A: Polym. Chem. 2003, 41, 3901.

[23] Miyatake, K.; Zhou, H.; Watanabe, M. Macromolecules 2004, 37, 4956.

[24] Miyatake, K.; Zhou, H.; Matsuo, T.; Uchida, H.; Watanabe, M. Macromolecules 2004, 37, 4961.

[25] Ye, X. H.; Bai, H.; Winston Ho, W. S.; J. Membr. Sci. 2006, 279, 570. 